Reprod. Nutr. Dévelop., 1987, 27 (1 B), 237-238.

\title{
Isolement et caractérisation des champignons anaérobies stricts du rumen de moutons. Premiers résultats
}

\author{
G. FONTY ( $(1)\left({ }^{4}\right)$, A. BRETON $\left({ }^{2}\right)$, M. FEVRE $\left({ }^{3}\right)$, Anne CITRON ( $\left.{ }^{1}\right)$, M. HEBRAUD $\left({ }^{3}\right)$, \\ Ph. GOUET (') \\ (1) Laboratoire de Microbiologie, I.N.R.A. Theix, 63122 Ceyrat. \\ (2) Laboratoire de Microbiologie, U.A. C.N.R.S. 45, Université de Clermont II, \\ 4, rue Ledru, 63000 Clermont-Ferrand. \\ (3) Laboratoire de Differenciation fongique, \\ Université Claude-Bernard, Lyon I, 69622 Villeurbanne Cedex. \\ (4) Laboratoire de Protistologie, \\ U.A. C.N.R.S. 138, Université de Clermont II, 63170 Aubière.
}

Summary. Anaerobic fungi were isolated from the rumen of five adult sheep fed a rich fiber diet and from the rumen of eleven young lambs. Most of the strains isolated were related to the Neocallimastix frontalis species. In the young lambs, the fungi appeared by 8 days after birth and disappeared 2 weeks later when the lambs were fed a concentrate diet.

L'existence de champignons anaérobies stricts dans le rumen est une découverte relativement récente (Orpin, 1975) qui n'a donné lieu jusqu'ici qu'à un nombre limité d'études (Bauchop, 1979 ; Orpin, 1983/84). Nos objectifs ont été d'isoler et d'identifier ces micro-organismes dans le rumen du mouton, de suivre leur apparition chez le jeune, et d'étudier quelques-unes de leurs propriétés enzymatiques.

Matériel et méthodes. Les prélèvements du contenu de rumen ont été effectués $30 \mathrm{~min}$ et une heure après le repas chez 5 moutons adultes fistulisés. Trois animaux recevaient en deux repas, $1400 \mathrm{~g}$ par jour d'un aliment composé de luzerne en pellets $(800 \mathrm{~g})$, de foin haché de prairie naturelle $(250 \mathrm{~g})$, de paille de blé hachée $(250 \mathrm{~g})$ et d'orge broyée $(150 \mathrm{~g})$. Un mouton recevait en deux repas par jour, $1260 \mathrm{~g}$ d'une ration composée de paille traitée à l'ammoniac $(800 \mathrm{~g})$, de pulpe de betteraves $(300 \mathrm{~g})$, de tourteau d'arachide $(125 \mathrm{~g})$ et d'un complément minéral ( $35 \mathrm{~g}$ ) et un autre mouton était nourri à volonté, uniquement avec du foin de luzerne.

L'implantation des champignons a été suivie depuis la naissance jusqu'à l'âge de 6 semaines chez 11 agneaux élevés en troupeau avec leurs mères et qui ont reçu un aliment concentré de finition à partir de l'âge de trois semaines.

Les souches ont été isolées sous $\mathrm{CO}_{2}$ par la méthode des roll tubes sur le milieu de Joblin (1981), puis entretenues sur le milieu de Orpin (Comm. personnellel complété de fragments de paille de blé, de sisal ou de papier filtre. Leur morphologie a été observée en microscopie optique et électronique à balayage et leur aptitude à dégrader ou à fermenter différents substrats carbonés a été évaluée. Les produits terminaux de la fermentation de ces substrats (acides gras volatils, acide lactique, éthanol, gaz) ont été analysés en chromatographie à phase gazeuse.

L'équipement enzymatique des champignons a été étudié en les cultivant sur des milieux contenant du cellobiose ou de I'hydroxyéthylcellulose. Les $\beta$ glucosidases et les cellulases ont été dosés en utilisant le p-nitrophényl- $\beta$-Dglucopyranoside et la carboxymethylcellulose comme substrats. 
Résultats et discussion. Les champignons anaérobies étaient présents dans le rumen de tous les moutons adultes. Chez les agneaux ils sont apparus au $8^{e}$ jour après la naissance et étaient présents chez tous entre les $10^{\mathrm{e}}$ et $20^{\mathrm{e}}$ jours $\left(10^{2}-10^{3}\right.$ zoospores. $\mathrm{ml}^{-1}$ ). Ils ont ensuite disparu chez 9 des 11 agneaux étudiés dès que l'aliment concentré a été distribué.

La majorité des souches isolées se caractérisait par des sporocystes globuleux ou ovoïdes $(50 \times 100 \mu \mathrm{m})$ pourvus de rhizoïdes ramifiés et de zoospores possédant plusieurs flagelles agrégés et mus par un mouvement synchrone, ce qui permet de les rattacher à l'espèce Neocallimastix frontalis. Ces souches ont dégradé le papier filtre, la paille, le sisal, le xylane (wood gum-NBC) et ont utilisé le glucose, lactose, cellobiose, saccharose, raffinose, mannose, maltose. Les principaux produits de la fermentation sont l'acétate, l'éthanol, le lactate et I'hydrogène.

Après 4 jours de culture l'hydroxyéthycellulose a induit spécifiquement la production et la sécrétion de $\beta$-glucosidases et de cellulases. Ces enzymes ont présenté une activité maximale pour des $\mathrm{pH}$ de 5 et 5,5 et pour des températures de 50 et $40^{\circ} \mathrm{C}$. D'autres activités comme les $\alpha$ - et $\beta$-xylosidases, $\alpha$-galactosidase n'ont pas été décelées.

Quelques souches, isolées seulement chez les agneaux, caractérisées par l'absence de rhizoïde et l'existence de zoospores munies d'un ou deux flagelles, sont en cours d'identification.

Avec des régimes riches en fourrages, Neocallimastix frontalis semble donc bien être un micro-organisme autochtone du rumen de mouton. Son implantation précoce chez le nouveau-né confirme, comme il a été montré précédemment (Fonty, 1984) que le rumen du jeune agneau, bien qu'encore non fonctionnel, héberge dans son rumen les principaux micro-organismes caractéristiques du ruminant : bactéries cellulolytiques et méthanogènes, protozoaires, champignons. La présence d'autres espèces de champignons phycomycètes pourrait être révélée en faisant varier les méthodes d'isolement et les milieux de culture. De même d'autres activités enzymatiques telles que les $\beta$-galactanases, arabinases, xylosidases, pourraient être mises en évidence à partir de milieux de culture contenant des inducteurs spécifiques.

Ce travail a été réalisé dans le cadre du programme de Recherche établi par le Groupement d'Intérêt Scientifique "Cellulolyse en rumen et en digesteur ».

Bauchop T., 1979. App. environ. Microbiol., 38, 148-158.

Fonty G., 1984. Thèse de Doctorat d'Etat $n^{\circ} 339$, Université de Clermont II.

Joblin K. N., 1981. Appl. environ. Microbiol., 42, 1119-1122.

Orpin G. G., 1975. J. gen. Microbiol., 91, 249-262.

Orpin G. G., 1983/84. Anim. Feed. Sci. Techn., 10, 121-143. 